\title{
Correction to: Mid-term results of medial open-wedge high tibial osteotomy based on radiological grading of osteoarthritis
}

\author{
Yasuhiro Takahara ${ }^{1}$ Hirotaka Nakashima ${ }^{1} \cdot$ Satoru Itani ${ }^{1} \cdot$ Haruyoshi Katayama $^{1} \cdot$ Kazuaki Miyazato $^{1}$. \\ Yuichi Iwasaki ${ }^{1} \cdot$ Hisayoshi Kato $^{1} \cdot$ Yoichiro Uchida ${ }^{1}$
}

Published online: 30 July 2021

๑) Springer-Verlag GmbH Germany, part of Springer Nature 2021

\section{Correction to: Archives of Orthopaedic and Trauma Surgery https://doi.org/10.1007/s00402-021-04011-x}

The original version of this article unfortunately contained a mistake. Error in Fig. 6 caption.

Figure 6 caption should read:

Case presentation of 67-year-old male with KL grade 2. A-E Pre-operative radiography of left-right knee before OWHTO. F, G Postoperative radiography after OWHTO (correction angle 10 degree). H-K Postoperative 10 years after OWHTO.

The original article has been corrected.
Publisher's Note Springer Nature remains neutral with regard to jurisdictional claims in published maps and institutional affiliations.

The original article can be found online at https://doi.org/10.1007/ s00402-021-04011-x.

Yasuhiro Takahara

yasuhiro_takahara@nkfh.or.jp

1 Department of Orthopedic Surgery, Nippon Kokan Fukuyama Hospital, 1844 Tsunoshita Daimon-cho, Fukuyama 721-0927, Japan 